\title{
DIAGNOSIS AND TREATMENT OF LIVER ABSCESSES
}

\author{
Ivanov K., V. Ignatov, N. Kolev, A. Tonev, D. Hristov, S. Konsulova, \\ B. Balev*, R. Madjov**. \\ Department of General and Operative Surgery, *Department of Imaging Diagnostics, \\ **Department of Hepato-Biliary Surgery ,University Hospital "St. Marina" - Varna, Bulgaria
}

Reviewed by: Assoc. Prof. R. Radev, MD, PhD

\begin{abstract}
Pyogenic abscesses are rare and difficult problem for modern surgery because of the high mortality rate. After the 70s of the last century the introduction of new image methods as ultrasound diagnostics, percutaneous and direct cholangiography and biliary drainage, guided aspiration, and percutaneous drainage of the abscess cavity dramatically changed both the diagnosis and treatment of these patients. The routine diagnostic methods are ultrasound and CT scan. Percutaneous aspiration and drainage under ultrasound or $\mathrm{CT}$ control is applied as first-line treatment of hepatic abscesses.
\end{abstract}

Keywords: liver, abscess, CT, ultrasound, percutaneous drainage

\section{INTRODUCTION}

Pyogenic abscesses are rare and difficult problem for modern surgery because of the high mortality rate. In the first 3 decades of the last century the most frequent reason fot that kind of disease - the pileflebitis, caused by apendicitis, in $75-80 \%$ of cases was the main reason for death. The most frequent cause for hepatic abscesses in the later periods of last century to nowadays were the bingn and malign obstructions of biliary tree, which caused multiple abscesses with total mortality about $45-50 \%$. After the 70's, with introducing of the methods for imaging diagnosis as ultrasonogrphy, percutaneus and endoscopic cholangiography and biliac drainage, directed aspiration and percutaneus drainage of abscesses's cavities. The diagnostics and treatment of such cases have changed dramaticly. At the same time more aggressive operative and non operative approaches for treatment of hepatobiliar and pancreatic neoplasm led to increasing the frequency of pyogenic hepatic abscesses as well as penetration of the infection to the liver on the way of hepatic arteria.

\section{AIM}

The aim of this study is to follow-up the epidemilogy, ethiology, bacteriology, diagnosis and treatment of hepatic abscesses in patients, treated in University Hospital "St. Marina", Varna.

\section{MATERIAL AND METHODS}

In University Hospital "St. Marina" for a period of 5 years /2002 to 2006/ were treated 47 patients with pyogenic hepatic abscesses, distributed in groups of age and sex as follows:

Table 1 Distribution of the patients with hepatic abscesses in groups of age and sex.

\begin{tabular}{||l|c|c|c|c|c|c||}
\hline \hline & $\mathbf{2 0 0 2}$ & $\mathbf{2 0 0 3}$ & $\mathbf{2 0 0 4}$ & $\mathbf{2 0 0 5}$ & $\mathbf{2 0 0 6}$ & Total \\
\hline Male & 5 & 4 & 6 & 10 & 2 & 27 \\
\hline Female & 2 & 1 & 3 & 9 & 6 & 21 \\
\hline \hline
\end{tabular}

The median age of the males was 44.4 years, and the median age of the females was 64.7 years.

\section{RESULTS}

In the past years the median age of male patients with heaptic abscesses decrese. В последните години средната възраст на пациентите с чернодробен абсцес намалява. The proportion male/female without statistical significance is with male prevalence.

\section{Ethiology}

In dependence of the way of infection's spread, the heaptic abscesses have an ethiological calssification in 6 grpups:

- Through the biliary ducts

- Through the portal vein

- Direct penetration of the agent

- By trauma

- Through the heaptic arteria

- Cryptogenic abscesses

The cholangiocarcinoma is the most frequent reason for malign obstruction in the past years. [30] The usage of internal 
biliar stents in such patients has reflection. The hepatic metastases are other frequent cause for presence of pyogenic process. The hepatic arteria become a source of infection in the past years, because the inreasing of immunosuppresed patiens and the arterial embolisation. [5,14].

The percent of patients with reducted hepatic function has droped, probably because the increased frequency of the abscceses in patients with biliar stents. [14].

\section{Diagnostics}

Routine methods for diagnosis are the ultrasonography and CT. The cholangiography remains important diagnostic tool for $30-40 \%$ of the patients. [14].

The CT is with highest sensibility - 93\%. That method could find abscesses with $0.5-1.0 \mathrm{~cm}$ in size and that make this method more sensible then ultrasonography (83\%). The cholangiography is indicated $2 / 3$ of hepatic abscesses, originated from biliary ducts. Radionucleoid examinataion of the liver and Ro-graphy of abdomen are less sensitive methods and are led away from the practice for diagnosis of hepatic abscesses.

\section{Microbiologic investigation}

Results for the microbilogical agents could be attained by taking a puncture from the hepatic cavity, blie ducts and hemocultures. The results from the puncture and bile ducts usually are positive, while only $55-60 \%$ of the hemocultures have bacterial growth. [14].

Table 2. Distribution of microbilogical agents

\begin{tabular}{||l|c|c|c||}
\hline \hline & Puncture & Hemoculture & Bile \\
\hline Byopsy & 88 & 82 & 50 \\
\hline Positive & 97 & 56 & 84 \\
\hline Anaerobs & 25 & 32 & 15 \\
\hline $\begin{array}{l}\text { Resistent } \\
\text { agents }\end{array}$ & 25 & 10 & 37 \\
\hline Fungi & 22 & 11 & 37 \\
\hline
\end{tabular}

According to the data in the literature, the most frequent agents are E. coli, Klebsiela, Streptococcus spp., as in the past years we can observe a tendency for decreasing the infections with $E$. Col, and increasing the infections caused by Klebsiela, Streptococcus spp. and Pseudomonas. A reason for this is the usage of stents. The significant increasing of the fungi infections is connected with usage of wide-spectered antibiotics in patients with biliary drainage in which there are often expression of cholangitis. From the anaerobic microbs the most common isolated are Bacteroides spp., Clostridia, Streptococcus spp. [3,6,34]. The most comon agents causing hepatic abscesses in the University Hospital "St. Marina" - Varna are PS. aeruginosa, E. coli, E. Faecalis, Seratia spp. All microbiologic agents were resistent to mass-applied beta-lactams. We have observed bacterial sensitvity to fluochinolons, aminoglucosides, and some of the bacterial strains are sensitive to macrolides and the strategical antibacterial drugs - carbapanems and cephalosporines ( 3 and 4 generation).

\section{Treatment}

In approximately $35 \%$ of the patients wourldwide drainage of abscces cavity is needed. The percutaneous drainage is applied as first step in the treatment in $45 \%$ of the patients. In a small per cent carefuly selected patients percutaneous aspiration without drainage is applied. [13,14,32,33]. In the surgical clinics in University Hospital "St. Marina" Varna as a method of choice in the treatment of hepatic abscesses is the application of percutaneous aspiration and draiange plcement under ultrasonographic or CT control and eventual lavage of the abscessic cavity after the aspiration. In single cases with selected patients with small sized abscesses aspiration of the cavity content without drainage placement is adequate. After that strict control of the cavity using the US or CT methods must be applied.

In all cases with hepatic abscesses we have applied paraenteral and antimicrobic treatment, which started with wide-spectered antibacterial combination and after identification of bacterial agent and his antibacterial sensitivity adequate drug therapy was prescribed.

\section{Mortality rate and the risk factors that increase it.}

The mortality, conneceted to hepatic abscesses decreases because of the multiple abscesses mortality drop. Increasing of mortality is observed only in through-hepatic arteria-penetrated infections. [14].

The risk factors connected with significant increase of mortality rate are [24]:

- Multiple abscesses

- Concomitant malignant disease

- Jaundice

- Hypoalbuminemia

- Leucocytosis

- Bacteriemia

- Fungal infection

- Septic chock

\section{CONCLUSION}

1. The freqency of hepatic abscesses is increased mainly because of the aggressive approach in treatment of hepatobiliary and pancreatic neoplasms.

2. The application of biliary stends changes bacterial flora in hepatic abscesses and the application of wide-spectered antibiotics in these patients leads to mixed bacterial infection and fungal infection.

3. The advantage of image diagnostic methods improves the diagnoses. The development of percutaneous drainage under CT control contibutes to significant decrease of the mortality.

4. The biliary tract obstruction and particularly the obstruction of malignant processes is the mos common 
reason of hepatic abscesses. Biliary drainage in patients with malignant biliary tree obstruction inproves the survival rate in patients underwent palliative or radical operation. In these patients, however the hepatic abscess is more rearly appeared with pain and normal hepatic function is observed.

5. There is an increase of the patients with hepatic metastases in which embolisation of hepatic artria is applied, also increased are the patients with heavy immunosuppresion in which hepatic abscesses was developed. [5,7,16].

6. The development of US and CT diagnosis contributes improvement of diagnostic approaces to many diseases. These examiantions make easier the early diagnosis of pyogenic abscesses and the application of percutaneous drainage and in that way improve the patients' prognosis. CT is diagnostic method of choice. MRI could be used for the adequate diagnosis, too. But using $\mathrm{CT}$ can increase the examination duration, also the high price and the lack of possibility for percutaneous drainage limitates the application of this method. [21].

7. The importance of anaerobic bacteria is noticed for a long time. Our data showed that there is no significant change in the frequency of hepatic abscesses caused by anaerobic bacteria during the past years. However, the apppearance of abscesses from multiresistent and mixed bacteria is comparatively new phenomenon. It is connected with comaratively high number of patients with biliary stents, recidiving cholangitis and multiple antibiotic treatments. The fungal superinfection that is noticed in patients with malignant blood diseases is in significance. $[5,7,18]$.

8. The application and improvement of percutaneous biliary drainage during the past decade changes significantly the treatment of patients with hepatic abscesses. Antibacterial therapy combined with percutaneous drainage gives excellent results. $[5,8,16,36,38]$. The application of percutanepus drainage is most appropriate for solitary hepatic lesion. The multiple abscesses caused by biliary tree obstruction could be treated by percutaneous drainage of the biliary ducts. Percutaneous and open drainage are most commonly known as aditional each others methods and the last one is applied in cases that the first one had not given success, as well as in patients that surgical intervention is needed because of other occasion. Indications for operative treatment are the multiple abscesses and the therapy with corticosteroides in patients with ascites.

9. The combination of percutaneous aspiration and antibacterial treatment is appropriate only in small number of cases of small solitary hepatic abscesses and precise image control. [7,11,36].

\section{REFERENCES}

1. Attar B, Levendoglu H, Cuasay NS. CT-guided percutaneous aspiration and catheter drainage of pyogenic liver abscesses. Am J Gastroenterol. 1986; 81:550 -555.

2. Baek SY, Lee MG, Cho KS, et al. Therapeutic percutaneous aspiration of hepatic abscesses: effectiveness in 25 patients. AJR Am J Roentgenol. 1993;160:799-802.

3. Barakate MS, Stephen MS, Waugh RC, et al. Pyogenic liver abscess: a review of 10 years' experience in management. Aust N Z J Surg. 1999;69:205-209.

4. Bertel CK, van Heerden JA, Sheedy PF 2nd. Treatment of pyogenic hepatic abscesses: surgical vs percutaneous drainage. Arch Surg. 1986; 121:554 -558 .

5. Branum GD, Tyson GS, Branum MA, Meyers WC. Hepatic abscess: changes in etiology, diagnosis and management. Ann Surg 1990; 212:655-662.

6. Chu KM, Fan ST, Lai EC, et al. Pyogenic liver abscess: an audit of experience over the past decade. Arch Surg. 1996;131:148 -152.

7. Civardi G, Filice C, Caremani M, et al. Hepatic abscesses in immunocompromised

8. Donovan AJ, Yellin AE, Ralls PW. Hepatic Abscess. World J Surg 1991; 15:162-169.

9. Farges O, Leese T, Bismuth H. Pyogenic liver abscess: an improvement in prognosis. Br J Surg. 1988;75:862- 865 .

10. Gerzof SG, Johnson WC, Robbins AH, et al. Intrahepatic pyogenic abscesses: treatment by percutaneous drainage. Am J Surg. 1985;149:487494.

11. Giorgio A, Tarantino L, Mariniello N, et al. Pyogenic liver abscesses: 13 years of experience in percutaneous needle aspiration with US guidance. $R a-$ diology 1995; 195:122-124.

12. Herbert DA, Fogel DA, Rothman J, et al. Pyogenic liver abscesses: successful non-surgical therapy. Lancet. 1982;1:134 -136.

13. Herman P, Pugliese V, Montagnini AL, et al. Pyogenic liver abscess: the role of surgical treatment. Int Surg. 1997;82:98 -101.

14. Huang CJ, Pitt HA, Lipsett PA, et al. Pyogenic hepatic abscess: changing trends over 42 years. Ann Surg. 1996;223:600-607.

15. Johnson RD, Mueller PR, Ferrucci JT Jr, et al. Percutaneous drainage of pyogenic liver abscesses. AJR Am J Roentgenol. 1985;144:463- 467.

16. Lambiase RE, Deyoe L, Cronan JT, et al. Percutaneous drainage of 335 consecutive abscesses: results ofprimary drainage with oneyear follow-up. Radiology 1992; 184:167-173.

17. Lipsett PA, Huang CJ, Lillemoe KD, et al. Fungal liver abscess: etiology and management. $J$ Gastrointest Surg.

18. Marcus SG, Walsh TJ, Pizzo PA, Danforth DN. Hepatic abscess in cancer patients. Arch Surg 1993; 128:1358-1364.

19. McDonald MI, Corey GR, Gallis HA, et al. Single and multiple pyogenic liver abscesses: natural 